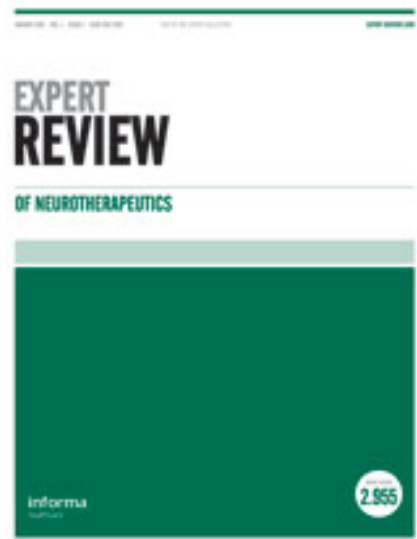

\title{
Metabolomics markers in Neurology: current knowledge and future perspectives for therapeutic targeting.
}

\begin{tabular}{|r|l|}
\hline Journal: & Expert Review of Neurotherapeutics \\
\hline Manuscript ID & ERN-2020--0055.R1 \\
\hline Manuscript Type: & Review (invited) \\
\hline Keywords: & $\begin{array}{l}\text { metabolomics, biochemical markers, metabolites, neurology, drug } \\
\text { targets }\end{array}$ \\
\hline
\end{tabular}

\section{SCHOLARONE Manuscripts}



for therapeutic targeting.

\section{Metabolomics markers in Neurology: current knowledge and future perspectives}

\section{Abstract}

Introduction: Metabolomics is an emerging approach providing new insights into the metabolic changes and underlying mechanisms involved in the pathogenesis of neurological disorders.

Areas covered: Here, we present an overview of the current knowledge of metabolic profiling (metabolomics) to provide critical insight on the role of biochemical markers and metabolic alterations in neurological diseases.

Expert opinion: Elucidation of characteristic metabolic alterations in neurological disorders is crucial for a better understanding of their pathogenesis, and for identifying potential biomarkers and drug targets. Nevertheless, discrepancies in diagnostic criteria, sample handling protocols, and analytical methods still affect the generalizability of current study results.

Keywords: metabolomics; biochemical markers; metabolites; neurology; drug targets.

\section{Highlights:}

- Metabolomics is an emerging approach providing new insights into individual metabolic profile.

- The investigation of characteristic metabolic alterations in neurological disorders is crucial for a better understanding of their pathogenesis.

- Metabolomics markers hold the potential of improving diagnosis, follow-up of patients, and clinical trial outcomes.

- Discrepancies in the phenotyping/classification of the neurological diseases and their subtypes, the mixed cohorts of patients and uncontrolled sampling conditions, have, to date, prevented identification of clear metabolic profiles and pathways. 


\section{Introduction}

The development of innovative tools, screening approaches, and imaging techniques has indeed improved the study of the biochemical or cellular mechanisms and their homeostasis in the central and peripheral nervous system. Genomics and proteomics have been widely explored in the last decades. Nevertheless, variations in transcriptional/translational processes determine that gene transcript levels do not always correlate with protein expression [1]. As a result, quantification of proteins might not always capture post-translational modification effects on protein synthesis [1]. More recently metabolic markers have offered promise to better understand and predict the development of neurological disorders [2].

Compared to genes and proteins, plasma metabolic profiling (metabolomics) presents the advantage of better reflecting the resulting interplay between environmental and genetic factors, and holds the potential of improving diagnosis, follow-up of patients, and clinical trial outcomes. In particular, metabolomics aims at identifying metabolites related to pathways implicated in the development and progression of the disorder, thus improving the knowledge about the disease pathogenesis [2].

\subsection{Metabolic pathways of the nervous system}

Brain energy-demands account for about $25 \%$ of total glucose source in our body, despite the lack of an energy-generating storage such as glycogen or fat. Neurons mostly rely on glucose supply for adenosine triphosphate (ATP) production, and accordingly mitochondria dysfunction and bioenergy deficits have long been proposed as the mechanism underlying chronic neuronal damage. Reduced energy metabolism 
has been well documented through the positron emission tomography (PET) scan analysis in neurodegenerative disorders [3-7].

Some authors proposed that astroglial and neuronal mitochondria oxidize not only glucose but a combination of substrates, including $\beta$-oxidation of fatty acids, pyruvate, lactate, and neuromediators such as glutamate and GABA $[8,9]$. Indeed, lipids play a critical role in central nervous system homeostasis, including formation of lipid rafts, maintenance of cell membrane structure, and involvement in signal transduction [1012]. It has been estimated that about $20 \%$ of the total energy requirement of the brain is provided by the oxidation of fatty acids [13]. The supplement of amino acids is less significant and, during gluconeogenesis and neuronal activity, the pool of amino acids must be constantly replaced by transamination of $\alpha$-ketoglutarate, pyruvate, or proteolysis of proteins.

The neuronal microenvironment is regulated by a well-organized neurovascular system which filters the exchange of biomolecules and xenobiotics through the bloodcerebrospinal fluid barrier. The model of the third circulation between the cerebrospinal and interstitial fluids (CSF and ISF) was first proposed in 1900 by Harvey Williams Cushing and Louis Weed [14-16]. Beyond the blood-brain barrier (BBB), a combination of intracellular and extracellular enzymes also contributes to the molecular trafficking with a metabolic barrier, which can metabolize and inactivate many neuroactive and toxic compounds $[17,18]$.

The peripheral nervous systems (PNS), compared to the central nervous system (CNS), is more exposed to toxic agents due to the presence of a less effective blood-nervous system barrier. Differently from the brain, peripheral nerves have a lower energy demand both at rest or under stimulation. Nerve axons and Schwann cells use a composite pattern of substrates for energy provision. They derive the major fraction of 
their composite energy requirements from glucose [19]. Ketone bodies can also contribute to part of the energy requirements [19]. Most of the glucose in peripheral nerves is preferentially taken up by Schwann cells [20], which hold the highest concentration of aldose reductase [21,22]. The polyol pathway plays a central role in peripheral nerve metabolism and survival in normoglycemic conditions [23]. Neurons in the dorsal root ganglia (DRG) also play a critical role in the metabolic support of the nerve, and apparently exhibit a greater capability of responding to metabolic insult through continuous synthesis and refolding of proteins than the axonal compartment $[24]$.

As a result of large energy stores and minor oxygen requirements, nerve metabolism can be adequately supported by anaerobically generated high energy phosphates. It has been previously demonstrated by Fink and colleagues that peripheral nerves can conduct impulses for a prolonged period of time even with a limited source of glucose [25]. It has been shown that nerves are able to adapt their oxygen consumption in conditions of reduced supply such as hypoxia [26] or aging [27]. Investigations have also outlined the importance of vesicular glycolysis as means of on-board energy for fast axonal transport [28].

\subsection{Metabolomics daily-cycle}

"Circadian metabolism" refers to the circadian $(24 \mathrm{~h})$ control of metabolism to optimize energy storage and utilisation across the day and night, by aligning the timing of sequentially dependent processes. In addition, these daily oscillating biochemical changes in human systemic and tissue-specific metabolic pathways are associated with the sleep/wake, feeding/fasting and light/dark state. Local metabolism is usually synchronized and driven by a central clock, located in the suprachiasmatic nuclei (SCN) 
in the light-responsive region of the anterior hypothalamus. The rhythmic production of the hormones, melatonin and cortisol, are directly regulated by the $\mathrm{SCN}$, therefore representing reliable markers of the phase of the central SCN clock [29]. In addition to these circadian endocrine rhythms, the circadian signal is also transmitted via sympathetic and parasympathetic neural circuits to the periphery. All mammalian tissues including the metabolically active liver, skeletal muscle and adipose tissue, express independent clocks. These local peripheral clocks (but not the clock in the $\mathrm{SCN})$ entrain to meal timing $[30,31]$ and are all well placed to regulate metabolic processing. Interestingly, glucocorticoids can also influence peripheral rhythmicity independently from central SCN control [32]. It has also been demonstrated that circadian clocks in liver, adipose tissue, muscle, and kidney are all highly based on nutrients supply and food intake [33-35]. There has been clear evidence in humans that most of detected metabolites show $24 \mathrm{~h}$ diurnal rhythmicity when the sleep/wake and feeding patterns are regular [36,37]. In these studies, most of the metabolite rhythms persisted during acute total sleep deprivation [36,37]. Endogenous circadian rhythms in metabolites/lipids have also been reported in humans when controlling/minimizing the confounding effects of activity, light, temperature, sleep, and food intake [38-40].

Therefore, when considering metabolite data, it is crucial to control the sampling time (time stamp) for an accurate interpretation. Accordingly, sequential sampling at regular time intervals across the $24 \mathrm{~h}$ day might more realistically reflect systemic metabolic pathways and dynamic tissue-related activity.

\subsection{Metabolomics approaches}

The human metabolome consists of thousands of metabolites, including water-soluble and lipid-soluble molecules [41-43]. Indeed, the multiple chemical properties and 
varying concentrations do not facilitate metabolite investigation. The application of multiple metabolomics tools has helped to extend metabolite coverage [44].

The classification of different metabolites and altered metabolic pathways has so far been based on either targeted [43] or untargeted methods [45]. The former approach mainly focuses on identifying and quantifying predefined metabolites/lipids. The latter by contrast addresses a more comprehensive analysis of metabolites/lipids, albeit less specific. Indeed, the combination of both targeted and untargeted analyses provide better repeatability and a more extensive investigation range [46].

Mass spectrometry (MS) and nuclear magnetic resonance (NMR) are the most widely used platforms. The combination of MS and chromatography separation technologies can reduce the complexity of biological samples, helping to differentiate isobaric compounds and reduce ionization suppression [47]. The main separation methods are based on gas chromatography (GC), liquid chromatography (LC) and capillary electrophoresis (CE). The development of gas chromatography-mass spectrometry (GC-MS) related metabolomics involves the detection of new metabolites with decreased false positive and false negative rates through rapid separation and automatic data processing. Gas chromatography consists of a two-step approach (derivatization and chromatographic separation) appropriate for analyzing volatile and semi-volatile metabolites, and it currently represents the most popular method. The accuracy of metabolite identification has been increased through a retention index (RI), and specific algorithms and software to facilitate metabolite investigation $[48,49]$ and data processing [50,51]. GC-MS has demonstrated advantages in identifying metabolites derived from the tricarboxylic acid (TCA) cycle, glycolysis, fatty acid and amino acid metabolic pathways. GC-MS metabolomics approaches have been used successfully to study cancer markers [52-54]. By contrast to GC-MS, LC-MS also covers non-volatile 
153 metabolites [55]. Ultra-high-performance LC (UHPLC) provides an accurate 154 separation of polar metabolites [56], whereas reversed-phase liquid chromatography 155 (RPLC) is ideal for hydrophobic metabolite detection. RPLC-MS related metabolomics 156 has been widely applied for detecting biomarkers [57,58], including fatty acids and 157 carnitines [59], and understanding disease mechanisms [60]. Capillary electrophoresis 158 (CE)-MS is indicated for central carbon metabolites, nucleotides, co-enzymes, sugar 159 nucleotides and amino acids [61,62], and it has been used inter alia in studies 160 concerning diabetes [63] and cancers [64].

161 Direct infusion mass spectrometry (DIMS) is currently the main stream lipidomics 162 method. NMR can provide structure information for metabolite identification and is 163 increasingly used in metabolomics studies. Two-dimensional (2D) NMR provides 164 increased resolution, albeit lower sensitivity [65,66]. Stable isotope tracer-based metabolomics (SITBM) and fluxomics approaches are instead focused on the 166 calculation of the in vivo rate of metabolic fluxes in pathways [67]. A number of 167 software packages and complex algorithms have been developed for precise 168 quantification of metabolite flux rates $[68,69]$. Fluxomics has also recently been applied 169 to investigate cancer [70] and the cell cycle [71].

170 Over recent years, many metabolomics studies have been developed for answering 171 clinical scientific issues and understanding disease pathogenesis [72]. Clinical demands 172 have promoted the development of quick, accurate, sensitive and relatively low-cost 173 technologies. Analytical methods used to conduct metabolomics studies include NMR, 174 GC-MS and LC-MS [73,74]. Indeed, MS and NMR provide complementary data and 175 both analytical platforms are often required for a comprehensive characterization of 176 compounds [74]. For instance, NMR can differentiate isobaric compounds and 177 positional isomers, while MS can identify certain functional groups such as sulfate and 
nitro groups, which are NMR silent [74]. For detailed descriptions of these analytical methods, we suggest a recent review of Gathungu and colleagues [74].

Quality and timing of clinical samples are also crucial $[75,76]$. Ideally fasting samples should be collected. Food composition will affect the metabolic profile thus knowledge of the meal content and timing prior to sampling will help to interpret the metabolomics results. In controlled metabolomics studies, meal timing and content should be standardized [36,37]. Preanalytical variables, including blood collection tubes, hemolysis, temperature and time before further processing, and number of freeze/thaws can significantly impact the metabolic profile $[75,76]$. Analyses on mealtime, temporal, and daily influence on metabolites revealed higher metabolome variability after the morning compared to the evening meal, with more pronounced variability in urine than blood [77]. Specifically, glucose and other sugars as well as phospholipids changed in the post-prandial state as well as citric acid compared to other metabolites. Accordingly, it would be relevant to standardize meals when studying TCA cycle involved diseases.

\subsection{Metabolomics and aging}

A better definition of the progressive change of the metabolome profile with aging might further disclose the mechanisms through which age influences disease development and progression from its early stages. Metabolites vary with age in different species, including mice [78-80]. Metabolomics studies on aged mouse brains revealed significant variations in amino acid and nucleotide metabolism [81]. Indeed, the role of oxidative stress in aging has been well recognized $[82,83]$. Oxidative stress can result from the disproportionate bioavailability of reactive species responsible for functional alterations related to aging. In particular, variations in the plasma levels of metabolites from beta-oxidation of fatty acids, glycophospholipid and sphingolipid 
metabolism, may be strongly associated with physiological aging [84]. Relevant changes in the constituents of cell membranes, including phospholipids (PLs) and sphingomyelins (SMs), acylcarnitines (ACs), and some amino acids, such as histidine, have been described with age progression [85].

Dysregulation of the immune system has also been theorized to be involved in the aging process [86]. Investigations on the murine transcriptome showed a negative correlation between systemic lipid metabolism and the immune response during aging [87]. Therefore, dysregulation of both the alteration in redox homeostasis and the immune system apparently contribute to ageing [86]. For example, peroxidation of cell membrane lipids in the elderly population might affect the capability of immune cells to react to mitogens $[88,89]$.

A number of studies have attempted to investigate the relationship between age, sex and the metabolite profile [85,90-95]. Darst and colleagues performed the first longitudinal analysis to capture age-related phenomena in the human metabolome [96]. The authors found relevant differences for both age and sex in levels of plasma lipid steroids, including androgens, progestins, and pregnenolones. Sphingolipids and fatty acid lipids were also significantly associated with increased age. Most of the age-related amino acids, namely glutamine and tyrosine, were augmented, conversely, histidine, threonine, tryptophan, leucine, and serine decreased. These results provided strong evidence that most plasma metabolites are highly influenced by aging with a greater effect on metabolites in women than men. Specifically, in line with previous studies, phosphatidylcholines and sphingolipids levels tended to be higher in women than men [90,95-97], while serum ACs were lower in women [90,96]. Unfortunately, the sampling protocols and collection time-points were not specified in these studies. The KORA F4 study also reported an increase in serum sphingolipids according to age in 
women, and increased ACs in both women and men [95]. Indeed, dramatic hormone changes and loss of ovarian function would influence metabolite values in women, whereas men experience a more progressive decline of hormones and fertility [98]. As a result, post-menopausal women exhibit an increase in SMs, fatty acids, ACs and LysoPCs $[99,100]$. Despite this sexual dimorphism in the plasma metabolomics profile, Jové and colleagues tried to identify novel metabolites presenting the same trend of variation in both genders as biomarkers of aging [101]. The authors demonstrated a decrease in specific lipids, namely vitamin D2-related compound, phosphoserine (40:5), monoacylglyceride (22:1), diacylglyceride (33:2), and resolvin D6, emerging with the aging process, independently of gender. Some studies also attempted to define the relationship between longevity and lipid profiles. In particular, Jovè and colleagues investigated the lipid pattern of centenarian subjects [102]. The authors reported a significantly higher average chain length and saturated fatty acid content, and a lower content of polyunsaturated fatty acids in centenarians compared to non-centenarians. Another study on human longevity reported a significant decrease in both alkyl and alkenyl lipids, with a reduced content in plasmalogens for alkenyl lipids, in centenarians compared to non-centenarians [103]. This specific compositional lipid pattern implies that the density of double bonds and susceptibility to peroxidation, which increases in relation to the number of double bonds per fatty acid [104], were significantly lower in centenarians compared to non-centenarians, indicating that ether lipids from centenarians are more resistant to lipid peroxidation.

\section{Metabolomics in neurodegenerative disorders}

The classification of neurodegenerative disorders has yet to be defined in terms of its mechanistic progression and pattern of deterioration [105]. Considering the significant 
impact at the social and economic level, the identification of markers reflecting neurological disease development or worsening might be fundamental for therapeutic intervention and clinical management.

\subsection{Amyotrophic lateral sclerosis}

There have been a number studies investigating metabolomics markers in amyotrophic lateral sclerosis (ALS). Bjornevik and colleagues in a recent study explored plasma metabolites suggestive of metabolic dysregulation years before the onset of the disease [106]. Results suggested that alterations in lipid metabolism are likely to be related to the earliest phases of the disorder [106]. This finding supports previous animal models showing a preference for lipids as a source of energy during the asymptomatic stage [107]. Others have observed an increase in the levels of ketone bodies, derived from the utilization of fatty acids, in patients affected by symptomatic ALS [108]. The restricted use of lipids as the fuel source in motoneurons is associated with increased oxidative stress [109], which determines neuroinflammation, mitochondrial dysfunction, and excitotoxicity [110], eventually resulting in cellular death. Cacabelos and colleagues investigated the chronic excitotoxicity changes in lipid composition in spinal cord samples from ALS patients [111]. The authors reported an increase in docosahexaenoic acid (DHA), a key lipid in nervous system homeostasis, with both enhanced concentrations of neuroprotective docosahexaenoic acid-derived resolvin D, and higher lipid peroxidation-derived molecules. This overload, involving the expression of DHA synthetic enzymes, could later on exacerbate cell stress by contributing to TDP-43 aggregation and motoneurons loss. Others investigated potential metabolic signatures in ALS through an untargeted metabolomics approach comparing cerebrospinal fluid (CSF) from ALS patients to controls [112]. Metabolome analysis correctly predicted the diagnosis of ALS in more than $80 \%$ of cases. In 
particular, concentrations of glutamate and ascorbate were found to be significantly higher in ALS patients than controls $(\mathrm{p}=0.0002)$. Investigations of the CSF metabolome in ALS patients with different mutations in the $\mathrm{Cu} / \mathrm{Zn}$-superoxide dismutase (SOD1) gene further disclosed a distinctively different metabolomics signature in patients carrying a D90A SOD1 mutation compared to other groups [113]. In particular, arginine, lysine, ornithine, serine, threonine and pyroglutamic acid were all found to be reduced in patients carrying a D90A SOD1 mutation, thus contributing most to the CSF signature. In this regard, the use of metabolomics as a means to understand pathway information in genome-wide association studies could be of great interest for interpreting the effects of different mutations in ALS subtypes.

Some studies have also revealed an increase in plasma cysteine [114,115], which plays an antioxidant role, and a decrease in methionine [116], an intermediate in the biosynthesis of cysteine, suggesting a compensatory mechanism for the oxidative stress state.

\subsection{Alzheimer's disease}

There has also been great advance in defining metabolomics changes associated with the central pathology of Alzheimer's disease (AD). In AD, metabolomics investigations have demonstrated a reduction in ethanolamine plasmalogens (PlsEtn) in both brain [117-119] and plasma [120,121]. Plasmalogens are essential endogenous antioxidants, which protect other PL, lipid and lipoprotein particles from oxidative stress [122]. As for ALS, analysis of CSF and blood of patients with AD revealed a decrease of several lipid classes, including PL, phosphatidylcholines (PCs), phosphatidylinositols, sphingolipids, lysophospholipids, SMs, and sterols [10,12,123,124], supporting the hypothesis of a metabolic imbalance towards oxidative stress in AD. Nevertheless, the time course of these metabolite changes in relation to $\mathrm{AD}$ progression remains to be 
elucidated. Han and colleagues described a significant depletion in sphingolipids, particularly those containing long aliphatic chains such as 22 and 24 carbon atoms, and decreased levels of ceramides in early AD patients compared to controls [125]. Others have highlighted the potential link between altered plasma ceramide levels and hippocampal volume loss in mild cognitive impairment (MCI), supporting the hypothesis that alterations in ceramide metabolism may be related to early neuropathological changes [126]. A very recent study from Bernath and colleagues has investigated the association of serum triglycerides in $\mathrm{AD}$ with neuroimaging and CSF biomarkers [127]. Results suggest that long-chain, polyunsaturated fatty acidcontaining triglycerides were significantly associated with $\mathrm{MCI}$ and $\mathrm{AD}$, as well as with hippocampal volume and entorhinal cortical thickness. Furthermore, in those participants carrying the APOE $\varepsilon 4$ allele these principal components were significantly associated with CSF $\beta$-amyloid1-42 values and entorhinal cortical thickness.

Concerning amino acid metabolism in $\mathrm{AD}$ patients, a reduction of branched-chain amino acids (BCAAs) [128,129], creatinine [129], and taurine [130] has been observed; while higher glutamate [130] and glutamine [131] levels were found. Interestingly, a metabolomics study on the entorhinal cortex has shown changes in the expression levels of deoxyguanosine, xanthosine and guanine in early stages of the disorder, followed by modifications in dGMP and glycine in advanced stages [132]. The observed regional differences in purine metabolism in $\mathrm{AD}$ cortex highlight the need for considering regional specificities as markers of regional vulnerability.

Niedzwiecki and collaborators have recently conducted a study aimed at identifying metabolic AD markers in CSF and blood samples [133]. This study has the advantage of comparing systemic metabolites (blood analysis) with products derived from the CNS (CSF analysis), thus overcoming the difficulty in interpreting previous results due 
to the use of different substrates [133]. The study involved two independent populations of $\mathrm{AD}$ patients who underwent CSF and blood collection. The results confirmed previous findings reporting elevated plasma glutamine in AD [134-139]. These glutamine levels were positively correlated with APOE-e4 genotype, and CSF t-Tau and p-Tau181 levels [133]. These authors thus suggested the possibility of using glutamine as a biomarker to identify AD patients susceptible to excitotoxicity. The study also found reduced levels of piperine, which was negatively associated with CSF p-Tau181. Reduction of piperine could be ascribed to its antioxidant [140], antiinflammatory [141], and anti-secretase [142] activities. The importance of Niedzwiecki's study [133] lies in the identification of metabolites reproducibility altered in AD dementia. Validation of sensitive and comprehensive lipid biochemistry platforms might further disclose the ability to analyze the different pathways that may be involved in $\mathrm{AD}$ in relation to clinical phenotype and genotype.

\subsection{Multiple Sclerosis}

Metabolomics approach has also been used to study Multiple Sclerosis (MS). Stoessel and colleagues reported a decrease in PCs and lysophosphatidylcholines (LysoPCs) during the primary progressive form of MS [143], whereas others observed a change in the ratio of LysoPC/PC lipid profile in the plasma of patients with clinically diagnosed relapsing-remitting MS [144] and in the CSF of patients with AD [145]. PCs are important for the structural supports of cells, and for anti-inflammatory signaling [146]. Altered metabolism of sphingolipids has also been described in both MS [147] and AD [127]. Sphingolipids are also involved in both the structural components of cell membranes and sustaining cellular signaling [148]. Myelin damage determines the release of its structural components in CSF and blood stream, which can be considered as potential biomarkers of the disease $[149,150]$. In MS, an increase in taurine 
353 concentration in the spinal cord and CSF has also been reported [151,152], possibly 354 related to the immunomodulatory and neuroprotective reaction against the progressive a different lipid profile at the time of diagnosis compared with non-MS subjects [153]. Specifically, an up-regulation of diglycerides and a down-regulation of triglycerides was observed. These findings point to the relevance of these lipids in this disorder and the significance of lipid trait characterization as a diagnostic tool. Targeted lipidomics analyses have also demonstrated that the lipid peroxidation marker 8-iso-prostaglandin F2 $\alpha$ is increased in CSF from MS patients [154]. In addition, an increased incidence of CSF protein lipoxidation from MS patients has been reported as a result of augmented free radical production. Further investigations with larger sample sizes, prospective study design and with the presence of a healthy-control group are required to further elucidate the significance of such results.

\subsection{Parkinson's disease}

It has been an ongoing challenge identifying metabolic measures of disease progression in Parkinson's disease (PD). Early biomarker investigations into PD progression have mainly focused on examining compounds of dopaminergic catabolism. Previous studies analyzed CSF homovanillate concentrations with inconsistent results [155]. A LC/MS metabolomics approach revealed a significant reduction of uric acid in PD patient plasma samples compared to controls; while an increase in glutathione was observed in response to oxidative damage [156]. Considering the well-known involvement of mitochondria [157] and the Autophagy-Lysosomal Pathway and the UbiquitinProteasome System [158], LeWitt and colleagues combined analysis of CSF and plasma metabolites in an effort to discover metabolomics markers of oxidative stress 
among the compounds found to be biomarkers of PD progression: theobromine, theophylline, paraxanthine, and 1-methylxanthine. Caffeine intake, which is also inversely associated with the risk of developing PD [160], and the depletion of striatal dopamine might influence purine metabolism, thus explaining such a result [161]. The authors also found variations in medium and long-chain fatty acids (5-dodecanoate, 3hydroxydecanoate, docosadienoate, and Preclinical models of rotenone-treated rats had previously revealed similar changes in systemic fatty acid metabolism in rats $[162,163]$. In a recent study, Fagotti and colleagues demonstrated in a rotenone-rat model, undergoing chronic sleep restriction, an increase in BAACs, tryptophan, phenylalanine, and lipoproteins [163]. Others have described marked variations of PCs and LysoPCs in 6-hydroxydopamine-treated rats [164].

\subsection{Huntington's disease}

Considering the growing evidence of impaired circadian rhythms in Huntington's disease (HD) animal models, Morton and colleagues investigated alterations in melatonin and cortisol levels in pre-symptomatic transgenic HD sheep [165]. The authors found normal concentrations of serotonin and cortisol, whereas levels of plasma melatonin were significantly elevated, thus suggesting a compensatory neuroprotective response of melatonin in the first stages of the disorder. A number of studies have reported raised levels of citrulline in both pre-clinical and clinical models of HD, suggesting a dysfunction in the urea and NO cycles [166-168]. The possible dysregulation of CCAAT-enhancer-binding proteins (C/EBP) due to mutant huntingtin has been proposed as a causative mechanism of argininosuccinic acid synthetase and argininosuccinase acid lyase suppression [166].

\subsection{Migraine}


402

403

404

405

406

407

408

409

410

411

412

413

414

415

416

417

418

419

420

421

422

423

424

Migraine is an episodic brain disorder ranking as the second most disabling disease worldwide. Suggestions of metabolic involvement in the pathogenesis of the disorder were proposed for the first time in 1935 [169], when hypoglycemic status was proposed as being responsible for the attack, and later in 1982 [170] as the role of hypoxic state and energy deficit was again raised. Unbalanced cerebral energy metabolism and/or oxidative stress due to fasting, exercise [171,172], dehydration, hypoxia [173,174] and lack of sleep [175] might indeed trigger or worsen the attack.

Functional MRI studies have demonstrated that brain ATP decreases by $16 \%$ between attacks in patients with migraine without aura differently from healthy controls [176]. This finding suggested that mitochondrial oxidative phosphorylation is impaired in the brain of patients with migraine during [177] and between migraine attacks [178-184]. Mitochondrial dysfunction in migraine attacks has also been shown by increased levels of ADP and decreased levels of organophoshates. Measurement of lactate has produced mixed results $[185,186]$. Intriguingly, patients with migraine with aura presented elevated levels of brain lactate, but not in those with migraine without aura [187-190].

It should be considered that stimulus-induced surges in cortical lactate are physiological [191], since lactate is normally provided by astrocytes to neurons as energy provision. Accordingly, the absence of a stimulus-induced increase in lactate levels in patients with migraine could be considered pathological [192]. Indeed, the metabolic abnormalities observed during a migraine attack might reflect counter-regulatory effects rather than pathogenic alterations [192].

\section{Metabolomics in peripheral neuropathies}


Peripheral neuropathies consist of a heterogeneous group of disorders characterized by peripheral nerve damage. A wide array of causes, ranging from metabolic and toxic to genetic, can be identified. Despite this apparent variety of etiologies, mitochondrial dysfunction seems to underlie the different types. In fact, a number of mutations related to mitochondrial activity have been demonstrated to be responsible for several forms of inherited neuropathies [193]. Over 80 causative genes [194,195] involved in myelin structure, axonal transport, cytoskeletal architecture, endosomal vesicular transport, and microtubule interaction have been identified [196]. Genetic testing has so far been based on algorithms, mainly related to the clinical phenotype and electrophysiological features [197]. Nevertheless, identification of a genetic profile assessing patients at high risk of peripheral neuropathy still represents an open challenge [198]. A recent study attempted to identify metabolite profiles of Charcot-Marie-Tooth-2D (CMT2D) on a GarsNmf $f^{249 /+}$ murine model [199]. The authors found a decrease in ascorbic acid and carnitine in the spinal cord and sciatic nerve, whereas glycine showed only a modest increase. Nevertheless, differences in serum ascorbic acid levels did not correlate with the decreased ascorbate in the spinal cord. Considering the variation in carnitine levels, a dysfunction in the transport of fatty acids into the mitochondria was then hypothesized [200]. Changes in the glycine levels were instead interpreted as impaired synaptic transmission. However, Bais and colleagues stressed the need for further investigations concerning the potential role of such metabolites as markers of nerve damage in the genetic forms of neuropathy [199].

Metabolic profiling of diabetic neuropathy, which represents the most prevalent form of peripheral nerve disease, has also been investigated. Rojas and collaborators examined alterations in the metabolic pathways of DRG and peripheral nerves in a streptozotocin (STZ)-induced type 1 diabetic murine model [201]. The experiment 
showed a trend for an early reduction of TCA metabolites, which became more evident in the later stage when sensory loss and nerve damage were clearly present. BCAA levels, namely valine (Val), isoleucine (Ile) and leucine (Leu), showed an increase, indicating a switch towards alternative energetic pathways. In addition, they observed a progressive rise in the levels of sorbitol with the advancing diabetic state, again suggesting a shift to a minor energetic route. The authors also reported an early inhibition of glycolytic enzymes in response to the hyperglycemic status. These progressive changes in energy utilization eventually resulting in tissue-specific dysfunction. Similarly, Freeman and colleagues investigated metabolic alterations in STZ-diabetic rats [23]. Interestingly, they found altered lipid metabolism in the distal sural nerve with an initial sparing of the DRG or the trigeminal nerve, confirming a specific distal-proximal pathogenesis in diabetic neuropathy. The different tissue composition might explain such observation. In particular, compared to the DRG and trigeminal nerve, which are essentially neuronal, in the sural nerve there is a high proportion of Schwann cells whose disruption can cause axonal degeneration/neuropathy. Despite presenting a less significant phenotypic change, the lack of support from the DRG was proposed to contribute to the axonal degeneration.

Metabolomics studies have also been used to investigate metabolic profiles and pathomechanisms of myelin disruption in inflammatory neuropathies. A recent metabolomics approach based on blood analysis proposed disordered lipid metabolism as an indicator for Guillain-Barre syndrome (GBS) and its subtypes [202]. In 2018, Park and colleagues examined potential CSF biochemical linkage associated with the pathology of three GBS, including acute inflammatory demyelinating polyneuropathy (AIDP), acute motor axonal neuropathy (AMAN), and Miller Fisher syndrome (MFS) [203]. Patients with GBS exhibited reduced conductance related to demyelination 
combined or not with axonal damage, which coupled with membrane lipid compounds. The CSF analysis of AMAN revealed significantly higher levels of SMs, suggestive of myelin damage [204], compared to the AIDP and MFS groups. In all three subtypes they observed elevated monoacylglycerols (1-monopalmitin and 1-monostearin) $[203,205]$ and reduced levels of acetate, suggestive of an abnormality in myelin lipid biosynthesis [203,206-208]. CSF glucose was present at considerably higher levels in the MFS group [203]. Moreover, the significantly lower levels of acetoacetate, creatinine [202,209,210], and pyruvate [186], additionally supported the hypermetabolic status in MFS [203]. Proteinogenic amino acids were instead reduced [203]. Compared to MFS, AIDP and AMAN presented increased fatty acids, suggesting either reduced myelin lipid biosynthesis or critical demyelination process [203]. The AIDP group was further characterized by the highest levels of lysoPCs, which have been proposed as strong macrophage activation agents [211].

Chemotherapy-induced peripheral neuropathy (CIPN) is a common drug-related adverse effect of anti-neoplastic treatment [212]. Despite the fact that a clear mechanism has yet to be defined, mitochondrial dysfunction [213-216], intraepidermal nerve fiber damage [215], dysfunctional ion channels [217-219], inflammatory and immune status [220-222] seems to contribute to the pathogenesis of nerve damage. $\mathrm{Wu}$ and colleagues investigated metabolomics changes in patients treated with paclitaxelinduced CIPN [223]. The ultra-performance liquid chromatography-electrospray ionization-mass spectrometer (UPLC-ESI-MS) analysis revealed a decrease of ePCs and lysoPCs, indoxyl sulfate, suprofen S-oxide, and 4-ethylphenylsulfate. Metabolism of fatty acids, which contributes to the biosynthesis of prostaglandins and cell membranes, and glycerophospholipids, which provide stability, permeability and fluidity to cell membranes, was primarily affected by paclitaxel. These findings support 
other previous studies reporting alterations in lipids (LysoPCs or PCs), organic acids and ketones in paclitaxel-related CIPN [224-226].

\section{Conclusion}

The use of metabolomics to study biological phenotyping of neurological disorders might indeed be the key for early recognition of dysfunctional regulation, that would also imply the need for a prompt and precise intervention tailored on a patient's profile.

Despite providing a comprehensive outline of thousands of metabolites, metabolomics analysis would further require correct data interpretation for a clear understanding of the involved networks, as potential drug targets.

In the last five decades, research on cancer has uncovered metabolic alterations of specific pathways in tumor cells determining their survival in stressful conditions and elevated proliferation. Reprogrammed metabolism in malignant cells determines the development and persistence of altered bioenergetics, augmented biosynthesis, and redox imbalance. Therefore, research has focused on the characterization of reprogrammed activities to determine tumor behavior, and limit tumor evolution.

Glycolysis is considered a physiological response to reduced oxygen availability. In cancer, the increase in glycolytic flux and derived metabolites support the enhanced metabolic demands through ancillary pathways [227]. Besides pyruvate from glycolysis, fatty acids and amino acid oxidation can provide substrates to the TCA cycle to maintain mitochondrial ATP production in malignant cells [228]. Lipid uptake is also important during conditions of metabolic stress, and hypoxia causes a state of dependence on desaturated fatty acids in support of protein biosynthesis [229].

Despite the relevant genetic and pathophysiological heterogeneity of neurological disorders, current studies seem to support a similar general induction of supplementary 
pathways with a different involvement according to the disease stage. Experimental models on metabolic reprogramming might be highly informative about the molecular mechanisms underlying aberrant signalling and altered metabolic fluxes. This might be relevant in terms of identification of a therapeutic window for specific clinical opportunities. It will then be critical to determine which pathways are likely to be involved for a viable therapeutic intervention.

\section{Expert opinion}

Traditional metabolomics consider the organism as a metabolic stable system and generally relies on samples taken only at one time point. Nevertheless, metabolism is a dynamic process that changes across the $24 \mathrm{~h}$ day to optimize energy utilization and storage in synchrony with the feeding/fasting and sleep/wake cycles. Over $50 \%$ of plasma metabolites exhibit diurnal $24 \mathrm{~h}$ rhythms in entrained normal living conditions [36,37]. The endogenous circadian timing system regulates some of these plasma metabolite and lipid rhythms [38-40]. In the mouse liver over $50 \%$ of metabolites have circadian rhythms [230]. It is thus challenging to define the true alteration of metabolic pathways merely by upregulation or down-regulation of metabolites without considering the dynamic changes in metabolism across the day. Most diurnal/circadian metabolomics studies, however, have so far overlooked the importance of subcellular localization of metabolites (i.e., mitochondrial vs. cytosolic pools).

Further considerations, for example, mapping of many identified metabolites to specific metabolic pathways is still an open issue, since biological knowledge has not kept up with the increased progress of detection. Many metabolites currently lack biological significance, although circadian metabolomics studies may help to provide a context from which to predict their metabolic pathways. Accordingly, the extent of the 
"targeted" metabolome is likely to significantly increase as more metabolite identities and related pathways are recognized.

The limitations inherent to the published studies need to be acknowledged, namely sample size concerns, and generalizability beyond the study's geographic region/cohort. It is also difficult to discern whether the observed biomarkers represent primary biochemical manifestations of disease progression or downstream changes of the disorder. It should also be pointed out that the source of the measured metabolites is often not known and could also derive from the diet and gut flora.

Standardized analytical methods and selection of an adequate sample size are therefore fundamental for reducing some of the potential artifacts. For example, there could be a confounding effect due to the influence of cholesterol lowering medication, which could give the appearance of lower lipid levels. In addition, the longitudinal effects of aging should be investigated for a correct interpretation of study results in pathological conditions. Considering that different panels of metabolites might produce different outcomes, the definition of a uniform analytical method targeting specific metabolic profiles might help to guarantee the repeatability and reproducibility of study results in neurological disorders.

Over the last 20 years, metabolomics technology has significantly advanced. Future development should focus on improving qualitative and quantitative accuracy and automatic data processing. To date, many biomarkers and differential metabolites have been found by metabolomics studies, but often with conflicting results. It is also likely that the imprecise phenotyping/classification of the neurological diseases and their subtypes, the mixed cohorts of patients (age, sex, medication) with uncontrolled sampling conditions (no control of feeding; time of day etc) has, to date, prevented the identification of clear metabolic profiles and pathways. The functional interpretation of 
metabolic biomarkers in relation to cell and subcell biology could indeed play an important role in clarifying neurological disease mechanisms and disease progression.

Acknowledgements: We thank the Metabolomics Core Facility at the University of Surrey.

Disclosures: G.C. is a recipient of a research grant from Associazione Italiana Ricerca sul Cancro (AIRC Progetto IG 2016 Id.18631). C.G. is a consultant to Disarm Therapeutics, Inc, Helsinn Healthcare SA, PledPharma AB, Seattle Genetics Inc., Toray; he is a non-voting member of the Board of Directors of The Peripheral Nerve Society; and he is Associate Editor, Journal of the Peripheral Nervous System. D.J.S. holds research grants from UK Biotechnology and Biological Sciences Research Council (BBSRC) Grants (BB/I019405/1 and BB/S01814X/1).

Conflict of Interest: The authors declare that there are no conflicts of interest relevant to this work.

\section{Funding sources for study: None.}




\section{References}

Papers of particular interest, published within the annual period of review, have been highlighted as: * of importance; **of considerable importance.

1. Zapalska-Sozoniuk M, Chrobak L, Kowalczyk K, Kankofer M. Is It Useful to Use Several "Omics" for Obtaining Valuable Results? Mol Biol Rep 2019 Jun;46(3):3597-3606. doi: 10.1007/s11033-019-04793-9.

2. Hassan-Smith G, Wallace GR, Douglas MR, Sinclair AJ. The role of metabolomics in neurological disease. J Neuroimmunol. 2012;248(1-2):48-52. doi:10.1016/j.jneuroim.2012.01.009

3. Friedland RP, Budinger TF, Ganz E, Yano Y, Mathis CA, Koss B, et al. Regional Cerebral metabolic alterations in dementia of the Alzheimer type: positron emission tomography with [18F] fluorodeoxyglucose. J Comput Assist Tomogr. 1983; 7:590-8.doi:10.1097/00004728-198308000-00003

4. Foster NL, Chase TN, Mansi L, Brooks R, Fedio P, Patronas NJ, et al. Cortical abnormalities in Alzheimer's disease. Ann Neurol. 1984; 16:649-54. doi:10.1002/ana.410160605

5. Minoshima S, Giordani B, Berent S, Frey KA, Foster NL, Kuhl DE. Metabolic reduction in the posterior cingulate cortex in very early Alzheimer's disease. Ann Neurol. 1997; 42:85-94. doi:10.1002/ana.410420114.

6. Sakamoto S, Ishii K, Sasaki M, Hosaka K, Mori T, Matsui M, et al. Differences in cerebral metabolic impairment between early and late onset types of Alzheimer's disease. J Neurol Sci 2002; 200:27-32. doi:10.1016/S0022$510 \times(02) 00114-4$ 
617 7. Ishii K, Sasaki H, Kono AK, Miyamoto N, Fukuda T, Mori E. Comparison of

618

619

620

621

622

623

624 gray matter and metabolic reduction in mild Alzheimer's disease using FDGPET and voxel-based morphometric MR studies. Eur J Nucl Med Mol Imaging. 2005; 32:959-63.doi:10.1007/s00259-004-1740-5.

8. Panov A, Schonfeld P, Dikalov S, Hemendinger R, Bonkovsky HL, Brooks BR. The neuromediator glutamate, through specific substrate interactions, enhances mitochondrial ATP production and reactive oxygen species generation in nonsynaptic brain mitochondria. J Biol Chem. 2009; 21 (284):14448-14456.

9. Panov AV, Kubalik N, Zinchenko N, et al. Metabolic and functional differences between brain and spinal cord mitochondria underlie different predisposition to pathology. Am J Physiol Regul Integr Comp Physiol. 2011; 4(300):844-854.

10. Trushina, E, Mielke MM. Recent advances in the application of metabolomics to Alzheimer's Disease. Biochim Biophys Acta. 2014; 1842;1232-1239. doi: 10.1016/j.bbadis.2013.06.014

11. Han J, Kaufman RJ. The role of ER stress in lipid metabolism and lipotoxicity. J Lipid Res. 2016 Aug; 57(8):1329-38. doi: 10.1194/jlr.R067595.

12. Yi, L., Liu, W., Wang, Z., Ren, D., and Peng, W. Characterizing Alzheimer's disease through metabolomics and investigating anti-Alzheimer's disease effects of natural products. Ann N Y Acad Sci. 2017 Jun;1398(1):130-141. doi: 10.1111/nyas. 13385 .

13. Ebert D, Haller RG, Walton ME. Energy contribution of octanoate to intact rat brain metabolism measured by $13 \mathrm{C}$ nuclear magnetic resonance spectroscopy. $\mathrm{J}$ Neurosci. 2003 Jul 2;23(13):5928-35. 
640

641

642

643

644

645

646

647

648

649

650

651

652

653

654

655

656

657

658

659

660

661

662

663

664

14. Weed LH, Cushing H. Studies on cerebrospinal fluid. VIII. The effect of pituitary extract upon its secretion (choroidorrhoea), Amer. J. Physiol., 1915; $36: 77-103$.

15. Weed LH. The cerebrospinal fluid. Physiol. Rev. 1922; 2:171-203.

16. Cushing H. Studies in lntracranial Physiology and Surgery. Oxford Univ. Press, London, 1926, 146.

17. Kasser TR, Deutch A, Martin RJ. Uptake and utilization of metabolites in specific brain sites relative to feeding status. Physiol Behav. 1986;36(6):11615.

18. el-Bacha RS, Minn A. Drug metabolizing enzymes in cerebrovascular endothelial cells afford a metabolic protection to the brain. Cell Mol Biol (Noisy-le-grand). 1999 Feb;45(1):15-23.

19. Greene, DA, Winegrad, AI. In vitro studies of the substrates for energy production and the effects of insulin on glucose utilization in the neural components of peripheral nerve. Diabetes. 1979; 28:878-87.

20. Véga C, Martiel JL, Drouhault D, Burckhart MF, Coles JA. Uptake of locally applied deoxyglucose, glucose and lactate by axons and Schwann cells of rat vagus nerve. J Physiol 2003; 546:551-564.

21. Ludvigson MA, Sorenson RL. Immunohistochemical localization of aldose reductase. I. Enzyme purification and antibody preparation-localization in peripheral nerve, artery, and testis. Diabetes 1980; 29:438-449.

22. Jiang Y, Calcutt NA, Ramos KM, Mizisin AP. Novel sites of aldose reductase immunolocalization in normal and streptozotocin-diabetic rats [published correction appears in J Peripher Nerv Syst 2007;12:64]. J Peripher Nerv Syst 2006; 11:274-285. 
23. Cortese A, Zhu Y, Rebelo AP, et al. Biallelic mutations in SORD cause a common and potentially treatable hereditary neuropathy with implications for diabetes. Nat Genet. 2020;52(5):473-481. doi:10.1038/s41588-020-0615-4

24. Freeman OJ, Unwin RD, Dowsey AW et al. Metabolic Dysfunction Is Restricted to the Sciatic Nerve in Experimental Diabetic Neuropathy. Diabetes. 2016 Jan;65(1):228-38.

25. Fink BR, Cairns AM. A bioenergetic basis for peripheral nerve fiber dissociation. Pain. 1982 Apr;12(4):307-17.

26. Low PA, Schmelzer JD, Ward KK, Yao JK. Experimental chronic hypoxic neuropathy: relevance to diabetic neuropathy. Am J Physiol. 1986 Jan;250(1 Pt 1):E94-9.

27. Low PA, Schmelzer JD, Ward KK. The effect of age on energy metabolism and resistance to ischaemic conduction failure in rat peripheral nerve. J Physiol. 1986 May; 374:263-71.

28. Zala D, Hinckelmann MV, Yu H, et al. Vesicular glycolysis provides on-board energy for fast axonal transport. Cell. 2013;152(3):479-491. doi:10.1016/j.cell.2012.12.029

29. **Skene DJ, Arendt J. Human circadian rhythms: physiological and therapeutic relevance of light and melatonin. Ann Clin Biochem. 2006 Sep;43(Pt 5):34453.

\section{Importance of melatonin on human circadian rhythms.}

30. Damiola F, Le Minh N, Preitner N, Kornmann B, Fleury-Olela F, Schibler U. Restricted feeding uncouples circadian oscillators in peripheral tissues from the central pacemaker in the suprachiasmatic nucleus. Genes Dev. 2000 Dec 1;14(23):2950-61. 
690

691

692

693

694

695

696

697

698

699

700

701

702

703

704

705

706

707

708

709

710

711

712

713

714

31. Stokkan KA, Yamazaki S, Tei H, Sakaki Y, Menaker M. Entrainment of the circadian clock in the liver by feeding. Science. 2001 Jan 19;291(5503):490-3.

32. Oster H, Challet E, Ott V, et al. The Functional and Clinical Significance of the 24-Hour Rhythm of Circulating Glucocorticoids. Endocr Rev. 2017 Feb $1 ; 38(1): 3-45$.

33. **Zani, F., Breasson, L., Becattini, B., Vukolic, A., Montani, J. P., Albrecht, U., et al. PER2 promotes glucose storage to liver glycogen during feeding and acute fasting by inducing Gys2 PTG and G L expression. Mol. Metab. 2013; 2:292-305. doi: 10.1016/j.molmet.2013.06.006

\section{Importance of nutrients supply and food intake on circadian clocks.}

34. Kornmann, B., Schaad, O., Bujard, H., Takahashi, J. S., and Schibler, U. System-driven and oscillator-dependent circadian transcription in mice with a conditionally active liver clock. PLoS Biol. 2007; 5:e34. doi: 10.1371/journal.pbio.0050034

35. Lamia KA, Storch KF, Weitz, CJ. Physiological significance of a peripheral tissue circadian clock. Proc.Natl. Acad. Sci. U.S.A. 2008; 105: 15172-15177. doi: 10.1073/pnas.0806717105

36. Davies, S. K., Ang, J. E., Revell, V. L., Holmes, B., Mann, A., Robertson, F. P., et al. Effect of sleep deprivation on the human metabolome. Proc. Natl. Acad. Sci. U.S.A. 2014; 111:10761-10766. doi: 10.1073/pnas.1402663111

37. **Honma A, Revell VL, Gunn PJ, Davies SK, Middleton B, Raynaud FI, Skene DJ. Effect of acute total sleep deprivation on plasma melatonin, cortisol and metabolite rhythms in females. Eur J Neurosci. 2020 Jan;51(1):366-378. doi: 10.1111/ejn.14411.

\section{Importance of sleep/wake state on diurnal rhythmicity.}


38. *Dallmann R, Viola AU, Tarokh L, Cajochen C, Brown SA. The human circadian metabolome. Proc Natl Acad Sci USA. 2012; 109:2625-2629.

\section{Overview on the circadian metabolome in humans.}

39. Kasukawa T, Sugimoto M, Hida A, et al. Human blood metabolite timetable indicates internal body time. Proc Natl Acad Sci USA 2012; 109:15036-15041.

40. Chua EC, Shui G, Lee IT, et al. Extensive diversity in circadian regulation of plasma lipids and evidence for different circadian metabolic phenotypes in humans. Proc Natl Acad Sci USA 2013; 110:14468-14473.

41. Wishart DS, Tzur D, Knox C, et al. HMDB: the human metabolome database. Nucleic acids research. 2007; 35:521-526.

42. Wishart DS, Knox C, Guo AC, Eisner R, et al. HMDB: a knowledgebase for the human metabolome. Nucleic acids research. 2009;37(783):603-610.

43. Weljie AM, Newton J, Mercier P, Carlson E, Slupsky CM. Targeted profiling: Quantitative analysis of H-1 NMR metabolomics data. Analytical chemistry. $2006 ; 78: 4430-4442$.

44. Surowiec, M. Karimpour, S. Gouveia-Figueira, J. Wu, et al. Multi-platform metabolomics assays for human lung lavage fluids in an air pollution exposure study. Analytical and Bioanalytical Chemistry. 2016; 408:4751-4764.

45. Contrepois K, Jiang L, Snyder M. Optimized Analytical Procedures for the Untargeted Metabolomic Profiling of Human Urine and Plasma by Combining Hydrophilic Interaction (HILIC) and Reverse-Phase Liquid Chromatography (RPLC)-Mass Spectrometry. Molecular \& Cellular Proteomics. 2015; 14:16841695.

46. Chen S, Kong H, Lu X, Li Y, Yin P, Zeng Z, Xu G. Pseudotargeted metabolomics method and its application in serum biomarker discovery for 
hepatocellular carcinoma based on ultra high-performance liquid chromatography/triple quadrupole mass spectrometry. Analytical chemistry. 2013; 85:8326-8333.

47. Khamis MM, Adamko DJ, El-Aneed A. Mass spectrometric based approaches in urine metabolomics and biomarker discovery. Mass spectrometry reviews. $2017 ; 36: 115-134$.

48. Matsuo T, Tsugawa H, Miyagawa H, Fukusaki E. Integrated Strategy for Unknown EI-MS Identification Using Quality Control Calibration Curve. Multivariate Analysis. EI-MS Spectral Database, and Retention Index Prediction, Analytical chemistry. 2017; 89:6766-6773.

49. Dossin E, Martin E, Diana P, Castellon A, Monge A, Pospisil A, Bentley M, Guy PA. Prediction Models of Retention Indices for Increased Confidence in Structural Elucidation during Complex Matrix Analysis: Application to Gas Chromatography Coupled with High-Resolution Mass Spectrometry. Analytical chemistry. 2016; 88:7539-7547.

50. Ni Y, Su M, Qiu Y, Jia W, Du X. ADAP-GC 3.0: Improved Peak Detection and Deconvolution of Co-eluting Metabolites from GC/TOF-MS Data for Metabolomics Studies. Analytical chemistry. 2016: 88:8802-8811.

51. Domingo-Almenara X, Brezmes J, Vinaixa M, Samino S, Ramirez N, RamonKrauel M, Lerin C, Diaz M, Ibanez L, Correig X, Perera-Lluna A, Yanes O. eRah: A Computational Tool Integrating Spectral Deconvolution and Alignment with Quantification and Identification of Metabolites in GC/MSBased Metabolomics, Analytical chemistry. 2016; 88:9821-9829. 
52. Shao Y, Ye G, Ren S, et al. Metabolomics and transcriptomics profiles reveal the dysregulation of the tricarboxylic acid cycle and related mechanisms in prostate cancer. Int J Cancer. 2018 Jul 15;143(2):396-407.

53. Ye G, Liu Y, Yin P, et al. Study of induction chemotherapy efficacy in oral squamous cell carcinoma using pseudotargeted metabolomics. Journal of proteome research. 2014; 13:829 1994-2004.

54. Zhou Y, Song R, Zhang Z, et al. The development of plasma pseudotargeted GC-MS metabolic profiling and its application in bladder cancer. Anal Bioanal Chem. 2016 Sep;408(24):6741-9. doi: 10.1007/s00216-016-9797-0.

55. Zhou J, Yin Y. Strategies for large-scale targeted metabolomics quantification by liquid chromatography-mass spectrometry. The Analyst. 2016; 141:63626373.

56. Chen J, Wang W, Lv S, Yin P, Zhao X, Lu X, Zhang F, Xu G. Metabonomics study of liver cancer based on ultra performance liquid chromatography coupled to mass spectrometry with HILIC and RPLC separations. Analytica chimica acta. 2009: 650:3-9.

57. Ren S, Shao Y, Zhao X, et al. Integration of Metabolomics and Transcriptomics Reveals Major Metabolic Pathways and Potential Biomarker Involved in Prostate Cancer. Molecular \& Cellular Proteomics. 2016; 15:154-163.

58. Luo P, Yin P, Hua R, et al. A Large-scale, multicenter serum metabolite biomarker identification study for the early detection of hepatocellular carcinoma. Hepatology. 2018; 67:662-675.

59. Zhou L, Wang Q, Yin P, et al. Serum metabolomics reveals the deregulation of fatty acids metabolism in hepatocellular carcinoma and chronic liver diseases. Anal Bioanal Chem. 2012; 926:203-213. 
60. Son J, Lyssiotis CA, Ying H, Wang X, et al. Glutamine supports pancreatic cancer growth through a KRAS-regulated metabolic pathway. Nature. 2013; 496:101-105.

61. Cieslarova Z, Lopes FS, do Lago CL, et al. Capillary electrophoresis tandem mass spectrometry determination of glutamic acid and homocysteine's metabolites: Potential biomarkers of amyotrophic lateral sclerosis. Talanta. 2017; 170:63-68.

62. Rodrigues KT, Mekahli D, Tavares MF, Van Schepdael A. Development and validation of a CE-MS method for the targeted assessment of amino acids in urine. Electrophoresis. 2016; 37:1039-1047.

63. Ciborowski M, Adamska E, Rusak M, et al. CE-MS-based serum fingerprinting to track evolution of type 2 diabetes mellitus. Electrophoresis. 2015 Sep; 36(18):2286-2293. doi: 10.1002/elps.201500021.

64. Hirayama A, Kami K, Sugimoto M, et al. Quantitative metabolome profiling of colon and stomach cancer microenvironment by capillary electrophoresis timeof-flight mass spectrometry. Cancer research. 2009; 69:4918-4925.

65. Bojstrup M, Petersen BO, Beeren SR, Hindsgaul O, Meier S. Fast and accurate quantitation of glucans in complex mixtures by optimized heteronuclear NMR spectroscopy. Analytical chemistry. 2013; 85:8802-8808.

66. Nagana Gowda GA, Raftery D. Whole Blood Metabolomics by 1H NMR Spectroscopy Provides a New Opportunity To Evaluate Coenzymes and Antioxidants. Analytical chemistry. 2017; 89:4620-4627.

67. Winter G, Kroemer JO. Fluxomics - connecting 'omics analysis and phenotypes. Environmental Microbiology. 2013; 15:1901-1916. 
68. Srour O, Young JD, Eldar YC. Fluxomers: a new approach for C-13 metabolic flux analysis. BMC Syst Biol. 2011 Aug 16; 5:129. doi: 10.1186/1752-0509-5129.

69. Nöh K, Droste P, Wiechert W. Visual workflows for 13 C-metabolic flux analysis. Bioinformatics. 2015; 31:346-354.

70. Aguilar E, Marin de Mas I, Zodda E, Marin S, et al. Metabolic Reprogramming and Dependencies Associated with Epithelial Cancer Stem Cells Independent of the Epithelial-Mesenchymal Transition Program. Stem Cells. 2016 May;34(5):1163-76. doi: 10.1002/stem.2286.

71. Ahn E, Kumar P, Mukha D, Tzur A, Shlomi T. Temporal fluxomics reveals oscillations in TCA cycle flux throughout the mammalian cell cycle. Mol Syst Biol. 2017 Nov 6;13(11):953. doi: 10.15252/msb.20177763.

72. Rhee EP, Gerszten RE. Metabolomics and cardiovascular biomarker discovery. Clin Chem 2012;58:139-47.

73. Wilson RB, Hoggard JC, Synovec RE. Fast, high peak capacity separations in gas chromatography-time-of-flight mass spectrometry. Anal Chem. 2012;84(9):4167-4173. doi:10.1021/ac300481k

74. **Gathungu RM, Kautz R, Kristal BS, Bird SS, Vouros P. The integration of LC-MS and NMR for the analysis of low molecular weight trace analytes in complex matrices. Mass Spectrom Rev. 2020;39(1-2):35-54. doi:10.1002/mas.21575

\section{Comprehensive review on metabolomics approaches.}

75. Yin $\mathrm{P}$, Peter A, Franken $\mathrm{H}$, et al. Preanalytical aspects and sample quality assessment in metabolomics studies of human blood. Clin Chem. 2013;59(5):833-845. doi:10.1373/clinchem.2012.199257 
76. Stevens VL, Hoover E, Wang Y, Zanetti KA. Pre-Analytical Factors that Affect Metabolite Stability in Human Urine, Plasma, and Serum: A Review. Metabolites. 2019;9(8):156. doi:10.3390/metabo9080156

77. Kim K, Mall C, Taylor SL, et al. Mealtime, temporal, and daily variability of the human urinary and plasma metabolomes in a tightly controlled environment. PLoS One. 2014;9(1):e86223. Published 2014 Jan 24. doi:10.1371/journal.pone.0086223

78. Houtkooper RH, Argmann C, Houten SM, et al. The metabolic footprint of aging in mice. Sci Rep. 2011; 1:134.

79. Son N, Hur HJ, Sung MJ, et al. Liquid chromatography-mass spectrometrybased metabolomic analysis of livers from aged rats. J Proteome Res. 2012; $11: 2551-2558$.

80. Calvani R, Brasili E, Praticò G, et al. Fecal and urinary NMR-based metabolomics unveil an aging signature in mice. Exp Gerontol. 2014; 49:5-11.

81. Ivanisevic J, Stauch KL, Petrascheck M, et al. Metabolic drift in the aging brain. Aging (Albany NY). 2016; 8:1000-1020.

82. Kregel, KC, Zhang, HJ. An integrated view of oxidative stress in aging: Basic mechanisms, functional effects, and pathological considerations. American Journal of Physiology. Regulatory, Integrative and Comparative Physiology, 2007; 292(1):18-36.

83. Findeisen, HM, Pearson, KJ, Gizard, F, Zhao Y, Qing H, Jones KL, et al. Oxidative stress accumulates in adipose tissue during aging and inhibits adipogenesis. PLoS ONE. 2011; 6(4):e18532.

84. Lee SH, Park S, Kim H, et al. Metabolomic approaches to the normal aging process. Metabolomics. 2014; 10:1268-1292. doi:10.1007/s11306-014-0663-9. 
862

863

864

865

866

867

868

869

870

871

872

873

874

875

876

877

878

879

880

881

882

883

884

885

85. Yu Z, Zhai G, Singmann P, et al. Human serum metabolic profiles are age dependent. Aging Cell. 2012 Dec;11(6):960-7. doi: 10.1111/j.14749726.2012.00865.x.

86. Chung, HY, Cesari M, Anton S, Marzetti E, Giovannini S, Seo AY, et al. Molecular inflammation: Underpinnings of aging and age-related diseases. Ageing Research Reviews. 2009; 8(1):18-30.

87. Hong SE, Heo HS, Kim DH, Kim MS, Kim CH, Lee J, et al. Revealing systemlevel correlations between aging and calorie restriction using a mouse transcriptome. Age. 2010; 32(1):15-30.

88. Choe $\mathrm{M}$, Jackson $\mathrm{C}, \mathrm{Yu}$ BP. Lipid peroxidation contributes to age-related membrane rigidity. Free Radic Biol Med. 1995 Jun;18(6):977-84.

89. Wick G, Grubeck-Loebenstein B. The aging immune system: primary and secondary alterations of immune reactivity in the elderly. Exp Gerontol. 1997 Jul-Oct;32(4-5):401-13.

90. Mittelstrass K, Ried JS, Yu Z, Krumsiek J, Gieger C, Prehn C, Roemisch-Margl W, Polonikov A, Peters A, Theis FJ, Meitinger T, Kronenberg F, Weidinger S, et al. Discovery of sexual dimorphisms in metabolic and genetic biomarkers. PLoS Genet. 2011; 7:e1002215.

91. Menni C, Kastenmüller G, Petersen AK, Bell JT, Psatha M, Tsai PC, Gieger C, Schulz H, Erte I, John S, Brosnan MJ, Wilson SG, Tsaprouni L, et al. Metabolomic markers reveal novel pathways of ageing and early development in human populations. Int J Epidemiol. 2013; 42:1111-19.

92. Krumsiek J, Mittelstrass K, Do KT, Stückler F, Ried J, Adamski J, Peters A, Illig T, Kronenberg F, Friedrich N, Nauck M, Pietzner M, Mook-Kanamori DO, 
886

887

888

889

890

891

892

893

894

895

896

897

898

899

900

901

902

903

904

905

906

907

908

et al. Gender-specific pathway differences in the human serum metabolome. Metabolomics. 2015; 11:1815-33.

93. Dunn WB, Lin W, Broadhurst D, Begley P, Brown M, Zelena E, Vaughan AA, Halsall A, Harding N, Knowles JD, Francis-McIntyre S, Tseng A, Ellis DI, et al. Molecular phenotyping of a UK population: defining the human serum metabolome. Metabolomics. 2015; 11:9-26.

94. Chaleckis R, Murakami I, Takada J, Kondoh H, Yanagida M. Individual variability in human blood metabolites identifies age-related differences. Proc Natl Acad Sci USA. 2016; 113:4252-59.

95. Rist MJ, Roth A, Frommherz L, Weinert CH, Krüger R, Merz B, Bunzel D, Mack C, Egert B, Bub A, Görling B, Tzvetkova P, Luy B, et al. Metabolite patterns predicting sex and age in participants of the Karlsruhe Metabolomics and Nutrition (KarMeN) study. PLoS One. 2017; 12:e0183228.

96. Darst BF, Koscik RL, Hogan KJ, Johnson SC, Engelman CD. Longitudinal plasma metabolomics of aging and sex. Aging (Albany NY). 2019 Feb 24;11(4):1262-1282.

97. Gonzalez-Covarrubias V, Beekman M, Uh HW, Dane A, Troost J, Paliukhovich I, van der Kloet FM, Houwing-Duistermaat J, Vreeken RJ, Hankemeier T, Slagboom EP. Lipidomics of familial longevity. Aging Cell. 2013; 12:426-34.

98. Vermeulen A. Andropause. Maturitas. 2000 Jan 15;34(1):5-15.

99. Auro K, Joensuu A, Fischer K, Kettunen J, Salo P, Mattsson H, Niironen M, Kaprio J, Eriksson JG, Lehtimäki T, Raitakari O, Jula A, Tiitinen A, et al. A metabolic view on menopause and ageing. Nat Commun. 2014; 5:4708. 
909 100. Ke C, Hou Y, Zhang H, Yang K, Wang J, Guo B, Zhang F, Li H, Zhou X, Li Y, 910 Li K. Plasma Metabolic Profiles in Women are Menopause Dependent. PLoS

911 One. 2015;10:e0141743.

101. Jové M, Maté I, Naudí A, et al. Human Aging Is a Metabolome-related Matter of Gender. J Gerontol A Biol Sci Med Sci. 2016;71(5):578-585. doi:10.1093/gerona/glv074

102. **Jové M, Naudí A, Gambini J, et al. A Stress-Resistant Lipidomic Signature Confers Extreme Longevity to Humans. J Gerontol A Biol Sci Med Sci. 2017;72(1):30-37. doi:10.1093/gerona/glw048

\section{Very interesting study on longevity metabolic profile in centenarians.}

103. **Pradas I, Jové M, Huynh K, et al. Exceptional human longevity is associated with a specific plasma phenotype of ether lipids. Redox Biol. 2019;21:101127. doi:10.1016/j.redox.2019.101127

\section{Very interesting study on longevity metabolic profile in centenarians.}

104. Yin $\mathrm{H}, \mathrm{Xu} \mathrm{L}$, Porter NA. Free radical lipid peroxidation: mechanisms and analysis. Chem Rev. 2011;111(10):5944-5972. doi:10.1021/cr200084z

105. Przedborski S, Vila M, Jackson-Lewis V. Neurodegeneration: what is it and where are we? J Clin Invest. 2003 Jan;111(1):3-10.

106. Bjornevik K, Zhang Z, O'Reilly ÉJ, et al. Prediagnostic plasma metabolomics and the risk of amyotrophic lateral sclerosis. Neurology. 2019 Apr 30;92(18):e2089-e2100. doi: 10.1212/WNL.0000000000007401.

107. Palamiuc L, Schlagowski A, Ngo ST, et al. A metabolic switch toward lipid use in glycolytic muscle is an early pathologic event in a mouse model of amyotrophic lateral sclerosis. EMBO Mol Med. 2015; 7:526-546. 
933 108. Kumar A, Bala L, Kalita J, et al. Metabolomic analysis of serum by (1) H NMR spectroscopy in amyotrophic lateral sclerosis. Clin Chim Acta. 2010; 411:563567.

109. Schonfeld P, Reiser G. Why does brain metabolism not favor burning of fatty acids to provide energy? Reflections on disadvantages of the use of free fatty acids as fuel for brain. J Cereb Blood Flow Metab. 2013; 33:1493-1499.

110. Tracey TJ, Steyn FJ, Wolvetang EJ, Ngo ST. Neuronal lipid metabolism: multiple pathways driving functional outcomes in Health and disease. Front Mol Neurosci. 2018; 11:10.

111. **Cacabelos D, Ayala V, Granado-Serrano AB, et al. Interplay between TDP43 and docosahexaenoic acid-related processes in amyotrophic lateral sclerosis. Neurobiol Dis. 2016;88:148-160. doi:10.1016/j.nbd.2016.01.007

Fascinating hypothesis on TDP-43 aggregation and motoneurons loss.

112. Blasco H, Corcia P, Pradat PF, et al. Metabolomics in cerebrospinal fluid of patients with amyotrophic lateral sclerosis: an untargeted approach via highresolution mass spectrometry. J Proteome Res. 2013;12(8):3746-3754. doi:10.1021/pr400376e

113. **Wuolikainen A, Andersen PM, Moritz T, Marklund SL, Antti H. ALS patients with mutations in the SOD1 gene have an unique metabolomic profile in the cerebrospinal fluid compared with ALS patients without mutations. Mol Genet Metab. 2012;105(3):472-478. doi:10.1016/j.ymgme.2011.11.201

\section{Relevant metabolomics signature in different ALS genotypes.}

114. Pean A, Steventon GB, Waring RH, Foster H, Sturman S, Williams AC. Pathways of cysteine metabolism in MND/ALS. J Neurol Sci. 1994; 124: 5961. 
958 115. Woolsey PB. Cysteine, sulfite, and glutamate toxicity: a cause of ALS? J Altern

959

960

961

962

963

964

965

966

967

968

969

970

971

972

973

974

975

976

977

978

979

980

981 Complement Med. 2008; 14:1159-1164.

116. Wuolikainen A, Moritz T, Marklund SL, Antti H, Andersen PM. Disease related changes in the cerebrospinal fluid metabolome in amyotrophic lateral sclerosis detected by GC/TOFMS. PLoS One. 2011; 6:17947.

117. Ginsberg L, Rafique S, Xuereb JH, Rapoport SI, Gershfeld NL. Disease and anatomic specificity of ethanolamine plasmalogen deficiency in Alzheimer's disease brain. Brain Res. 1995; 698:223-226.

118. Han X, Holtzman DM, McKeel DW Jr. Plasmalogen deficiency in early Alzheimer's disease subjects and in animal models: molecular characterization using electrospray ionization mass spectrometry. J Neurochem. 2001; 77: 11681180. In depth characterization of the deficiency of brain plasmalogens in Alzheimer's disease, utilizing tandem quadrapole mass spectrometry.

119. Han X. Lipid alterations in the earliest clinically recognizable stage of Alzheimer's disease: implication of the role of lipids in the pathogenesis of Alzheimer's disease. Curr Alzheimer Res 2005; 2:65-77.

120. Goodenowe DB, Cook LL, Liu J, et al. Peripheral ethanolamine plasmalogen deficiency: a logical causative factor in Alzheimer's disease and dementia. J Lipid Res. 2007 Nov;48(11):2485-98.

121. Wood PL, Mankidy R, Ritchie S, et al. Circulating plasmalogen levels and Alzheimer Disease Assessment Scale-Cognitive scores in Alzheimer patients. J Psychiatry Neurosci. 2010 Jan;35(1):59-62.

122. Brites P, Waterham H, Wanders R. Functions and biosynthesis of plasmalogens in health and disease. Biochim Biophys Acta. 2004;1636(2-3):219-31. 
982 123. Oresic M, Hyotylainen T, Herukka SK, Sysi-Aho M, Mattila I, Seppanan-

983

984

985

986

987

988

989

990

991

992

993

994

995

996

997

998

999

1000

1001

1002

1003

1004

1005

Laakso T, et al. Metabolome in progression to Alzheimer's disease. Transl.

Psychiatry. 2011; 1:e57. doi: 10.1038/tp.2011.55

124. $\mathrm{Xu} \mathrm{XH,} \mathrm{Huang} \mathrm{Y,} \mathrm{Wang} \mathrm{G,} \mathrm{Chen} \mathrm{SD.} \mathrm{Metabolomics:} \mathrm{a} \mathrm{novel} \mathrm{approach} \mathrm{to}$ identify potential diagnostic biomarkers and pathogenesis in Alzheimer's disease. Neurosci. Bull. 2012; 28:641-648. doi: 10.1007/s12264-012-1272-0.

125. Han X, Rozen S, Boyle SH, et al. Metabolomics in early Alzheimer's disease: identification of altered plasma sphingolipidome using shotgun lipidomics. PLoS One. 2011;6(7):e21643. doi:10.1371/journal.pone.0021643

126. Mielke MM, Bandaru VV, Haughey NJ, Rabins PV, Lyketsos CG, et al. Serum sphingomyelins and ceramides are early predictors of memory impairment. Neurobiol of Aging 2010;31: 17-24.

127. **Bernath MM, Bhattacharyya S, Nho K, et al. Serum triglycerides in Alzheimer disease: Relation to neuroimaging and CSF biomarkers. Neurology. 2020;94(20):e2088-e2098. doi:10.1212/WNL.0000000000009436

\section{Very interesting correlation of metabolic profile and AD features.}

128. Toledo JB, Arnold M, Kastenmuller G, Chang R, Baillie RA, Han X, et al. Metabolic network failures in Alzheimer's disease: a biochemical road map. Alzheimers Dement. 2017; 13:965-984. doi: 10.1016/j.jalz.2017.01.020.

129. Tynkkynen J, Chouraki V, van der Lee SJ, Hernesniemi J, Yang Q, Li S, et al. Association of branched-chain amino acids and other circulating metabolites with risk of incident dementia and Alzheimer's disease: a prospective study in eight cohorts. Alzheimers Dement. 2018; 14:723-733. doi: 10.1016/j.jalz.2018.01.003. 

1006
1007
1008
1009
1010
1011
1012
1013
130. Chouraki V, Preis SR, Yang Q, Beiser A, Li S, Larson MG, et al. Association of amine biomarkers with incident dementia and Alzheimer's disease in the Framingham Study. Alzheimers Dement. 2017; 13:1327-1336. doi: $10.1007 / \mathrm{s} 00415-017-8647-0$.
131. van der Lee SJ, Teunissen CE, Pool R, Shipley MJ, Teumer A, Chouraki V, et al. Circulating metabolites and general cognitive ability and dementia: evidence from 11 cohort studies. Alzheimers Dement. 2018; 14:707-722. doi: 10.1016/j.jalz.2017.11.012

1014

1015

1016

1017

1018

1019

1020

1021

1022

1023

1024

1025

1026

1027

1028

1029

1030

132. Ansoleaga B, Jové M, Schlüter A, et al. Deregulation of purine metabolism in Alzheimer's disease. Neurobiol Aging. 2015;36(1):68-80. doi:10.1016/j.neurobiolaging.2014.08.004

133. **Niedzwiecki MM, Walker DI, Howell JC, et al. High-resolution metabolomic profiling of Alzheimer's disease in plasma. Ann Clin Transl Neurol. 2020 Jan;7(1):36-45. doi: 10.1002/acn3.50956.

\section{Comparison of metabolic AD markers in both CSF and blood samples.}

134. Graham SF, Holscher C, Green BD. Metabolic signatures of human Alzheimer's disease (AD): 1H NMR analysis of the polar metabolome of postmortem brain tissue. Metabolomics. 2014;10(4:744-753).

135. Kaddurah-Daouk R, Zhu H, Sharma S, et al. Alterations in metabolic pathways and networks in Alzheimer's disease. Transl Psychiatry. 2013;3:e244.

136. Kaddurah-Daouk R, Rozen S, Matson W, et al. Metabolomic changes in autopsy-confirmed Alzheimer's disease. Alzheimers Dement 2011; 7:309-317.

137. Tukiainen T, Tynkkynen T, Meakinen V-P, et al. A multimetabolite analysis of serum by 1H NMR spectroscopy: Early systemic signs of Alzheimer's disease. Biochem Biophys Res Comm 2008; 375:356-361. 
1031 138. Czech C, Berndt P, Busch K, et al. Metabolite profiling of Alzheimer's disease

1032

1033

1034

1035

1036

1037

1038

1039

1040

1041

1042

1043

1044

1045

1046

1047

1048

1049

1050

1051

1052

1053

1054

1055 cerebrospinal fluid. PLoS ONE 2012; $7:$ e31501.

139. Motsinger-Reif AA, Zhu H, Kling MA, et al. Comparing metabolomic and pathologic biomarkers alone and in combination for discriminating Alzheimer's disease from normal cognitive aging. Acta Neuropathol Commun 2013; 1:28.

140. Mittal R, Gupta RL. In vitro antioxidant activity of piperine. Methods Find Exp Clin Pharmacol 2000; 22:271-274.

141. Mujumdar AM, Dhuley JN, Deshmukh VK, et al. Antiinflammatory activity of piperine. Jpn J Med Sci Biol 1990; 43:95-100.

142. Murata K, Matsumura S, Yoshioka Y, et al. Screening of beta-secretase and acetylcholinesterase inhibitors from plant resources. J Nat Med 2015; 69:123129.

143. *Stoessel D, Stellmann JP, Willing A, et al. Metabolomic profiles for primary progressive multiple sclerosis stratification and disease course monitoring. Front Hum Neurosci. 2018; 12:226.

Metabolomics application for diagnosis and differentiations of SM subtypes.

144. Del Boccio P, Pieragostino D, Di Ioia M, et al. Lipidomic investigations for the characterization of circulating serum lipids in multiple sclerosis. J Proteomics. $2011 ; 74: 2826-2836$.

145. Mulder C, Wahlund LO, Teerlink $\mathrm{T}$, Blomberg $\mathrm{M}$, et al. Decreased lysophosphatidylcholine/phosphatidylcholine ratio in cerebrospinal fluid in Alzheimer's disease. J Neural Transm. 2003; 110:949-955.

146. Treede I, Braun A, Sparla R, Kuhnel M, et al. Anti-inflammatory effects of phosphatidylcholine. J Biol Chem.2007; 282:27155-27164. 
1056

1057

1058

1059

1060

1061

1062

1063

1064

1065

1066

1067

1068

1069

1070

1071

1072

1073

1074

1075

1076

1077

1078

147. Miller Jr LG, Young JA, Ray SK, et al. Sphingosine toxicity in EAE and MS: evidence for ceramide generation via serine-palmitoyltransferase activation. Neurochem Res. 2017; 42:2755-2768.

148. Hannun YA, Obeid LM. Principles of bioactive lipid signalling: lessons from sphingolipids. Nat Rev Mol Cell Biol. 2008 Feb;9(2):139-50. doi: $10.1038 / \mathrm{nrm} 2329$.

149. Diestel A, Aktas O, Hackel D, et al. Activation of microglial poly(ADP-ribose)polymerase- 1 by cholesterol breakdown products during neuroinflammation: a link between demyelination and neuronal damage. J Exp Med. 2003; 198:17291740.

150. Safaiyan S, Kannaiyan N, Snaidero N, et al. Age-related myelin degradation burdens the clearance function of microglia during aging. Nat Neurosci. 2016; 19:995-998.

151. Garseth M, White LR, Aasly J. Little change in cerebrospinal fluid amino acids in subtypes of multiple sclerosis compared with acute polyradiculoneuropathy. Neurochem Int. 2001; 39:111-115.

152. Musgrave T, Tenorio G, Rauw G, Baker GB, Kerr BJ. Tissue concentration changes of amino acids and biogenic amines in the central nervous system of mice with experimental autoimmune encephalomyelitis (EAE). Neurochem Int. $2011 ; 59: 28-38$.

153. Nogueras L, Gonzalo H, Jové M, et al. Lipid profile of cerebrospinal fluid in multiple sclerosis patients: a potential tool for diagnosis. Sci Rep. 2019;9(1):11313. Published 2019 Aug 5. doi:10.1038/s41598-019-47906-x 
1079 154. Gonzalo H, Brieva L, Tatzber F, et al. Lipidome analysis in multiple sclerosis 1080 1081 1082 1083 1084 1085 1086 1087 1088 1089 1090 1091 1092 1093

156. **Bogdanov M, Matson WR, Wang L, et al. Metabolomic profiling to develop blood biomarkers for Parkinson's disease. Brain. 2008;131(Pt 2):389-396. doi:10.1093/brain/awm304

\section{Relevant study on metabolomics blood markers in PD.}

157. Carvalho C, Correia SC, Cardoso S, et al. The role of mitochondrial disturbances in Alzheimer, Parkinson and Huntington diseases. Expert Rev Neurother. 2015;15: 867-884.

158. Vilchez D, Saez I, Dillin A. The role of protein clearance mechanisms in organismal ageing and age-related diseases. Nat Commun. 2014;5:5659.

159. LeWitt PA, Li J, Lu M, Guo L, Auinger P; Parkinson Study Group-DATATOP Investigators. Metabolomic biomarkers as strong correlates of Parkinson disease progression. Neurology. 2017 Feb 28;88(9):862-869. doi: 10.1212/WNL.0000000000003663.

160. Palacios N, Gao X, McCullough ML, et al. Caffeine and the risk of Parkinson's disease in a large cohort of men and women. Mov Disord. 2013; 27:1276-1282.

161. Loeffler DA, LeWitt PA, Juneau PL, et al. Altered guanosine and guanine concentrations in rabbit striatum following increased dopamine turnover. Brain Res Bull. 1998; 45: 297-299. 
1104

1105

1106

1107

1108

1109

1110

1111

1112

1113

1114

1115

1116

1117

1118

1119

1120

1121

1122

1123

1124

1125

1126

1127

162. Tyurina YY, Polimova AM, Maciel E, et al. LC/MS analysis of cardiolipins in substantia nigra and plasma of rotenonetreated rats: implication for mitochondrial dysfunction in Parkinson's disease. Free Radic Res. 2015; 49:681-691.

163. Fagotti J, Targa ADS, Rodrigues LS, et al. Chronic sleep restriction in the rotenone Parkinson's disease model in rats reveals peripheral early-phase biomarkers. Sci Rep. 2019 Feb 13;9(1):1898. doi: 10.1038/s41598-018-376576.

164. Farmer K, Smith CA, Hayley S, Smith J. Major alterations of phosphatidylcholine and lysophosphotidyl lipids in the substantia nigra using an early stage model of Parkinson's disease. Int J Mol Sci. 2015; 16:18865-18877.

165. **Morton AJ, Middleton B, Rudiger S, Bawden CS, Kuchel TR, Skene DJ. Increased plasma melatonin in presymptomatic Huntington disease sheep (Ovis aries): Compensatory neuroprotection in a neurodegenerative disease? J Pineal Res. 2020 Mar; 68(2):e12624. doi: 10.1111/jpi.12624.

Highlight on variations of melatonin in the first stages of HD.

166. Chiang MC, Chen HM, Lee YH, et al. Dysregulation of C/EBPalpha by mutant Huntingtin causes the urea cycle deficiency in Huntington's disease. Hum Mol Genet. 2007.;16: 483-498.

167. Chen CM, Lin YS, Wu YR, et al. High protein diet and Huntington's disease. PLoS One. 2015 May 19;10(5):e0127654. doi: 10.1371/journal.pone.0127654.

168. Skene DJ, Middleton B, Fraser CK, et al. Metabolic profiling of presymptomatic Huntington's disease sheep reveals novel biomarkers. Sci Rep. 2017 Feb 22; 7:43030. doi: 10.1038/srep43030. 
1128

1129

1130

1131

1132

1133

1134

1135

1136

1137

1138

1139

1140

1141

1142

1143

1144

1145

1146

1147

1148

1149

1150

1151

169. Gray PA, Burtness HI. Hypoglycemic headache. Endocrinology. 1935: 19:549560.

170. Amery WK. Brain hypoxia: the turning- point in the genesis of the migraine attack? Cephalalgia. 1982; 2:83-109.

171. Pingitore A, Lima GP, Mastorci F, Quinones A, Iervasi G, Vassalle C. Exercise and oxidative stress: potential effects of antioxidant dietary strategies in sports. Nutrition. 2015; 31:916-922.

172. Powers SK, Radak Z, Ji LL. Exercise- induced oxidative stress: past, present and future. J Physiol. 2016; 594:5081-5092

173. Schoonman GG, Evers DJ, Terwindt GM, van Dijk JG, Ferrari MD. The prevalence of premonitory symptoms in migraine: a questionnaire study in 461 patients. Cephalalgia. 2006; 26:1209-1213.

174. Arngrim N, Schytz HW, Britze J, et al. Migraine induced by hypoxia: an MRI spectroscopy and angiography study. Brain. 2016 Mar;139(Pt 3):723-37. doi: 10.1093/brain/awv359.

175. Trivedi MS, Holger D, Bui AT, Craddock TJA, Tartar JL. Short- term sleep deprivation leads to decreased systemic redox metabolites and altered epigenetic status. PloS One. 2017;12:e0181978.

176. Reyngoudt H, Paemeleire K, Descamps B, De Deene Y, Achten E. 31P- MRS demonstrates a reduction in high- energy phosphates in the occipital lobe of migraine without aura patients. Cephalalgia. 2011; 31:1243-1253.

177. Welch KM, Levine SR, D’Andrea G, Schultz LR, Helpern JA. Preliminary observations on brain energy metabolism in migraine studied by in vivo phosphorus 31 NMR spectroscopy. Neurology. 1989; 39:538-541. 
1152

1153

1154

1155

1156

1157

1158

1159

1160

1161

1162

1163

1164

1165

1166

1167

1168

1169

1170

1171

1172

1173

1174

1175

178. Barbiroli B, Montagna P, Cortelli P, et al. Abnormal brain and muscle energy metabolism shown by 31P magnetic resonance spectroscopy in patients affected by migraine with aura. Neurology. 1992 Jun;42(6):1209-14.

179. Montagna P, Cortelli P, Monari L, et al. 31P-magnetic resonance spectroscopy in migraine without aura. Neurology. 1994 Apr;44(4):666-9.

180. Lodi R, Montagna P, Soriani S, et al. Deficit of brain and skeletal muscle bioenergetics and low brain magnesium in juvenile migraine: an in vivo 31P magnetic resonance spectroscopy interictal study. Pediatr Res. 1997 Dec;42(6):866-71.

181. Lodi R, Iotti S, Cortelli P, et al. Deficient energy metabolism is associated with low free magnesium in the brains of patients with migraine and cluster headache. Brain Res Bull. 2001 Mar 1;54(4):437-41.

182. Schulz UG, Blamire AM, Corkill RG, Davies P, Styles P, Rothwell PM. Association between cortical metabolite levels and clinical manifestations of migrainous aura: an MR- spectroscopy study. Brain. 2007 Dec;130(Pt 12):310210.

183. Kim JH1, Kim S, Suh SI, Koh SB, Park KW, Oh K. Interictal metabolic changes in episodic migraine: a voxel-based FDG- PET study. Cephalalgia. 2010 Jan;30(1):53-61. doi: 10.1111/j.1468-2982.2009.01890.x.

184. Reyngoudt H, Achten E, Paemeleire K. Magnetic resonance spectroscopy in migraine: what have we learned so far? Cephalalgia. 2012; 32:845-859

185. Watanabe H, Kuwabara T, Ohkubo M, Tsuji S, Yuasa T. Elevation of cerebral lactate detected by localized $1 \mathrm{H}$ - magnetic resonance spectroscopy in migraine during the interictal period. Neurology. 1996; 47:1093-1095 
1176

1177

1178

1179

1180

1181

1182

1183

1184

1185

1186

1187

1188

1189

1190

1191

1192

1193

1194

1195

1196

1197

1198

1199

1200

186. Sándor PS, Dydak U, Schoenen J, et al. MR- spectroscopic imaging during visual stimulation in subgroups of migraine with aura. Cephalalgia. 2005 Jul;25(7):507-18.

187. Prescot A, Becerra L, Pendse G, et al. Excitatory neurotransmitters in brain regions in interictal migraine patients. Mol Pain. 2009 Jun 30;5:34. doi: 10.1186/1744-8069-5-34.

188. Reyngoudt H, Paemeleire K, Dierickx A, et al. Does visual cortex lactate increase following photic stimulation in migraine without aura patients? A functional (1)H- MRS study. J Headache Pain. 2011 Jun;12(3):295-302. doi: 10.1007/s10194-011-0295-7.

189. Mohamed RE, Aboelsafa AA, Al- Malt AM. Interictal alterations of thalamic metabolic concentration ratios in migraine without aura detected by proton magnetic resonance spectroscopy. Egypt. J Radio. Nucl Med. 2013; 44:859870.

190. Becerra L, Veggeberg R, Prescot A, et al. A 'complex' of brain metabolites distinguish altered chemistry in the cingulate cortex of episodic migraine patients. Neuroimage Clin. 2016 Mar 31;11:588-594. doi: 10.1016/j.nicl.2016.03.020.

191. Sappey-Marinier D, Calabrese G, Fein G, Hugg JW, Biggins C, Weiner MW. Effect of photic stimulation on human visual cortex lactate and phosphates using 1H and 31P magnetic resonance spectroscopy. J Cereb Blood Flow Metab. 1992 Jul;12(4):584-92.

192. **Gross EC, Lisicki M, Fischer D, Sándor PS, Schoenen J. The metabolic face of migraine from pathophysiology to treatment. Nat Rev Neurol. 2019 Nov;15(11):627-643. 


\section{Interesting review on metabolic alterations underlying migraine.}

193. Niemann A, Berger P, SuterU. Pathomechanisms of mutant proteins in CharcotMarie-Tooth disease. Neuromolecular Med. 2006; 8:217-242.

194. Timmerman, V., Strickland, A. V. and Züchner, S. (2014). Genetics of CharcotMarie-Tooth (CMT) disease within the frame of the human genome project success. Genes 5, 13-32.

195. Fridman V, Bundy B, Reilly MM et al. (2015). CMT subtypes and disease burden in patients enrolled in the Inherited Neuropathies Consortium natural history study: a crosssectional analysis. J Neurol Neurosurg Psychiatry 86: 873878.

196. Klein CJ, Duan X, Shy ME (2013). Inherited neuropathies: clinical overview and update. Muscle Nerve 48: 604-622.

197. Saporta AS, Sottile SL, Miller LJ et al. (2011). Charcot-Marie-Tooth disease subtypes and genetic testing strategies. Ann Neurol 69: 22-33.

198. Argyriou AA, Bruna J, Genazzani AA, Cavaletti G. Chemotherapy-induced peripheral neurotoxicity: management informed by pharmacogenetics. Nat Rev Neurol. 2017 Aug;13(8):492-504. doi: 10.1038/nrneurol.2017.88.

199. Bais P, Beebe K, Morelli KH, et al. Metabolite profile of a mouse model of Charcot-Marie-Tooth type 2D neuropathy: implications for disease mechanisms and interventions. Biol Open. 2016 Jul 15;5(7):908-20.

200. Callander N, Markovina S, Eickhoff J, et al. Acetyl-L-carnitine (ALCAR) for the prevention of chemotherapy-induced peripheral neuropathy in patients with relapsed or refractory multiple myeloma treated with bortezomib, doxorubicin and low-dose dexamethasone: a study from theWisconsin Oncology Network. Cancer Chemother Pharmacol. 2014; 74: 875-882. 
1226 201. **Rojas DR, Kuner R, Agarwal N. Metabolomic signature of type 1 diabetes-

1227

1228

1229

1230

1231

1232

1233

1234

1235

1236

1237

1238

1239

1240

1241

1242

1243

1244

1245

1246

1247

1248

1249 induced sensory loss and nerve damage in diabetic neuropathy. J Mol Med (Berl). 2019 Jun;97(6):845-854. doi: 10.1007/s00109-019-01781-1.

\section{Comprehensive investigations on metabolic profiling of diabetic} neuropathy.

202. Tang HY, Chiu DT, Lin JF, et al. Disturbance of Plasma Lipid Metabolic Profile in Guillain-Barre Syndrome. Sci Rep. 2017 Aug 15;7(1):8140. doi: 10.1038/s41598-017-08338-7.

203. Park SJ, Kim JK, Kim HH, et al. Integrative metabolomics reveals unique metabolic traits in Guillain-Barré Syndrome and its variants. Sci Rep. 2019 Jan 31;9(1):1077.

204. Capodivento, G. et al. Sphingomyelin as a myelin biomarker in CSF of acquired demyelinating neuropathies. Scientific reports. 2017; 7:7831.

205. Park SJ, Jeong IH, Kong BS, et al. Disease type-and status-specific alteration of CSF metabolome coordinated with clinical parameters in inflammatory demyelinating diseases of CNS. PLoS One. 2016 Nov 17;11(11):e0166277. doi: 10.1371/journal.pone.0166277.

206. Chakraborty, G., Mekala, P., Yahya, D., Wu, G. \& Ledeen, R. W. Intraneuronal $\mathrm{N}$-acetylaspartate supplies acetyl groups for myelin lipid synthesis: evidence for myelin-associated aspartoacylase. Journal of neurochemistry. 2001; 78:736745.

207. Karelson, G., Ziegler, A., Künnecke, B. \& Seelig, J. Feeding versus infusion: a novel approach to study the NAA metabolism in rat brain. NMR in biomedicine. $2003 ; 16: 413-423$. 
208. Moffett, J. R., Ross, B., Arun, P., Madhavarao, C. N. \& Namboodiri, A. M. NAcetylaspartate in the CNS: from neurodiagnostics to neurobiology. Progress in neurobiology. 2007; 81:89-131.

209. Fujiwara S, Oshika H, Motoki K, et al. Diabetic ketoacidosis associated with Guillain-Barré syndrome with autonomic dysfunction. Internal medicine. 2000 Jul 10;89(7):1398-414.

210. Wang Y, Li G, Yang S, et al. Fasting glucose levels correlate with disease severity of Guillain-Barré Syndrome. PloS one. 2015; 10:e0145075.

211. Ghasemlou N, Jeong SY, Lacroix S, David S. T cells contribute to lysophosphatidylcholine-induced macrophage activation and demyelination in the CNS. Glia. 2007; 55:294-302.

212. Cavaletti G, Cornblath DR. Chemotherapy-induced peripheral neurotoxicity: Facts, needs and future directions. J Peripher Nerv Syst. 2019 Oct;24 Suppl 2:S86-S87. doi: 10.1111/jns.12332.

213. André N, Braguer D, Brasseur G, Gonçalves A, Lemesle-Meunier D, Guise S, et al. Paclitaxel induces release of cytochrome $\mathrm{c}$ from mitochondria isolated from human neuroblastoma cells. Cancer Res. 2000; 60:5349-5353.

214. Bernardi P, Krauskopf A, Basso E, Petronilli V, Blachly-Dyson E, Di Lisa F, et al. The mitochondrial permeability transition from in vitro artifact to disease target. FEBS J. 2006; 273:2077-2099.

215. Flatters SJ, Bennett GJ. Studies of peripheral sensory nerves in paclitaxelinduced painful peripheral neuropathy: evidence for mitochondrial dysfunction. Pain. 2006; 122:245-257. 
1273

1274

1275

1276

1277

1278

1279

1280

1281

1282

1283

1284

1285

1286

1287

1288

1289

1290

1291

1292

1293

1294

1295

1296

1297

216. Martin LJ, Gertz B, Pan Y, Price AC, Molkentin JD, Chang, Q. The mitochondrial permeability transition pore in motor neurons: involvement in the pathobiology of ALS mice. Exp. Neurol. 2009; 218:333-346.

217. Xiao W, Boroujerdi A, Bennett GJ, Luo ZD. Chemotherapyevoked painful peripheral neuropathy: analgesic effects of gabapentin and effects on expression of the alpha-2-delta type-1 calcium channel subunit. Neuroscience. 2007; 144: $714-720$.

218. Nieto FR, Entrena JM, Cendán CM, Pozo ED, Vela JM, Baeyens JM. Tetrodotoxin inhibits the development and expression of neuropathic pain induced by paclitaxel in mice. Pain. $2008 ; 137: 520-531$.

219. Zhang YY, Li G, Che H, Sun HY, Li X, Au WK, et al. Characterization of functional ion channels in human cardiac c-kit+ progenitor cells. Basic Res. Cardiol. 2014;109:407.

220. Ledeboer A, Jekich BM, Sloane EM, Mahoney JH, Langer SJ, Milligan ED, et al. Intrathecal interleukin-10 gene therapy attenuates paclitaxel-induced mechanical allodynia and proinflammatory cytokine expression in dorsal root ganglia in rats. Brain Behav. Immun. 2007; 21:686-698.

221. Dutra RC, Bicca MA, Segat GC, Silva KA, Motta EM, Pianowski LF, et al. The antinociceptive effects of the tetracyclic triterpene euphol in inflammatory and neuropathic pain models: the potential role of PKCepsilon. Neuroscience. 2015; 303:126-137.

222. Li D, Huang ZZ, Ling YZ, Wei JY, Cui Y, Zhang XZ, et al. Up-regulation of CX3CL1 via Nuclear Factor-kappaB-dependent Histone Acetylation Is Involved in Paclitaxel-induced Peripheral Neuropathy. Anesthesiology. 2015; 122:1142-1151. 
223. Wu FZ, Xu WJ, Deng B, Liu SD, Deng C, Wu MY, Gao Y, Jia LQ. Wen-LuoTong. Decoction Attenuates Paclitaxel-Induced Peripheral Neuropathy by Regulating Linoleic Acid and Glycerophospholipid Metabolism Pathways. Front Pharmacol. 2018 Aug 28;9: 956.

224. Patwardhan AM, Akopian AN, Ruparel NB, et al. Heat generates oxidized linoleic acid metabolites that activate TRPV1 and produce pain in rodents. J. Clin Invest. 2010; 120:1617-1626.

225. Wang HY, Tsai YJ, Chen SH, Lin CT, Lue JH. Lysophosphatidylcholine causes neuropathic pain via the increase of neuronal nitric oxide synthase in the dorsal root ganglion and cuneate nucleus. Pharmacol. Biochem Behav. 2013; 106:4756.

226. Sisignano M, Angioni C, Park CK, et al. Targeting CYP2J to reduce paclitaxelinduced peripheral neuropathic pain. Proc Natl Acad Sci. U.S.A. 2016; 113: $12544-12549$.

227. Lunt SY, Vander Heiden MG. Aerobic glycolysis: Meeting the metabolic requirements of cell proliferation. Annu Rev Cell Dev Biol. 2011; 27:441-464.

228. Ahn CS, Metallo CM. Mitochondria as biosynthetic factories for cancer proliferation. Cancer Metab. 2015; 3:1.

229. Young RM, Ackerman D, Quinn ZL, et al. Dysregulated mTORC1 renders cells critically dependent on desaturated lipids for survival under tumor-like stress. Genes Dev. 2013; 27:1115-1131.

230. Krishnaiah SY, Wu G, Altman BJ, et al. Clock Regulation of Metabolites Reveals Coupling between Transcription and Metabolism. Cell Metab. 2017 Apr 4;25(4):961-974.e4. doi: 10.1016/j.cmet.2017.03.019. 